\title{
A Five-Year Multicenter Study of the Susceptibility of the Bacteroides fragilis Group Isolates to Cephalosporins, Cephamins, Penicillins, Clindamycin, and Metronidazole in the United States
}

\author{
Kenneth E. Aldridge, Michael Gelfand, \\ L. Barth Reller, Leona W. Ayers, \\ Carl L. Pierson, Fritz Schoenknecht, \\ Richard C. Tilton, Jeanette Wilkinst, \\ Amy Henderberg, Denise D. Schiro, \\ Marlene Johnson, Aileen Janney, and \\ Charles V. Sanders
}

Over 2800 clinical strains of the Bacteroides fragilis group were collected during a 5-year period from ten geographically separate sites and tested for their susceptibility to various antimicrobial agents using a broth microdilution method. Among the cephalosporins, ceftizoxime was the most active (13\% resistance) and importantly exhibited relatively equal activity against both $\mathrm{B}$. fragilis species and non-B. fragilis species. Cefotaxime exhibited similar activity with an overall resistance rate of $18 \%$. Both ceftriaxone and cefoperazone were appreciably less active cephalosporins especially against non-B. fragilis species. With regard to cephamycins, cefoxitin $\left(M_{1} C_{90}, 32\right.$ $\mu \mathrm{g} / \mathrm{ml})$ was more active than cefotetan $\left(\mathrm{MIC}_{90}, \geqslant 256 \mu \mathrm{g} / \mathrm{ml}\right)$

From the Louisiana State University Medical Center (K.E.A., A.H., D.S., M.J., A.J., C.V.S.), New Orleans, Louisiana; the Methodist Hospital (M.G.), Memphis, Tennessee; the Duke University Medical Center (L.B.R.), Durham, North Carolina; the Ohio State University College of Medicine (L.W.A.), Columbus, Ohio; the University of Michigan Medical Center (C.L.P.), Ann Arbor, Michigan; the University of Washington Medical Center (F.S.), Seattle, Washington; the University of Connecticut School of Medicine (R.C.T.), Farmington, Connecticut; and the Los Angeles County-USC Medical Center (J.W.), Los Angeles, California, USA. and cefmetazole $\left(\mathrm{MIC}_{90}, 64 \mu \mathrm{g} / \mathrm{ml}\right)$. Non-B. fragilis species were highly resistant to cefotetan and cefmetazole. Imipenem was highly active against all strains with the exception of four strains of B. fragilis. Ampicillin-sulbactam, amoxicillin-clavulanate, piperacillin-tazobactam, and cefoperazone-sulbactam were all highly active with resistance rates $<2 \%$. No resistance was detected to metronidazole, whereas $14 \%$ of isolates were resistant to clindamycin. When compared with other studies, these findings underscore the wide variability in susceptibility patterns reported nationwide and the need to continue monitoring these patterns to aid in choosing the most active compounds for therapy.

Dr. Tilton's current address: North American Laboratory Group, Ltd., New Britain, Connecticut, USA.

tDeceased.

Address reprint requests to Dr. K.E. Aldridge, Department of Medicine, Section of Infectious Diseases, LSU Medical Center, 1542 Tulane Avenue, New Orleans, LA 70112, USA.

Received 13 August 1993; revised and accepted 1 December 1993.

(C) 1994 Elsevier Science Inc.

655 Avenue of the Americas, New York, NY 10010

$0732-8893 / 94 / \$ 7.00$ 


\section{INTRODUCTION}

The importance of anaerobic bacteria in mixed aerobic-anaerobic infections is well established (Finegold and George, 1989). Members of the Bacteroides fragilis group are the most important and most frequently isolated anaerobes from human infections. Of the various species within the $B$. fragilis group, the $B$. fragilis species is the most commonly isolated and tends to be the most susceptible to a variety of antimicrobial agents, especially $\beta$-lactams (Aldridge et al., 1984; Tally et al., 1985). It must be emphasized, however, that members of the non- $B$. fragilis species (B. distasonis, B. ovatus, B. thetaiotaomicron, and $B$. vulgatus) can comprise from $35 \%$ to $45 \%$ of the clinical isolates of the $B$. fragilis group (Brook, 1988; Cuchural et al., 1988). Furthermore, strains of the non- $B$. fragilis species tend to be highly resistant to certain antibiotics, especially $\beta$-lactams (Aldridge et al., 1988; Aldridge and Sanders, 1987; Goldstein and Citron, 1988). We performed a 5-year, multicenter study of the in vitro susceptibility of clinical isolates of the $B$. fragilis group. This report details the results of that study from 1987 to 1991 . Some of our results contrast with those of other recent multicenter studies.

\section{MATERIALS AND METHODS}

\section{Organisms}

Over a 5-year period, clinical isolates of the $B$. fragilis group were collected from ten medical centers within the United States and sent to a single reference laboratory (Louisiana State University in New Orleans) for susceptibility testing. A total of 2876 strains were tested, comprised of $1681 B$. fragilis, 484 $B$. thetaiotaomicron, 329 B. ovatus, 181 B. distasonis, $165 \mathrm{~B}$. vulgatus, $25 \mathrm{~B}$. uniformis, $10 \mathrm{~B}$. caccae, and $1 \mathrm{~B}$. eggerthi. All isolates were identified by using selective media, biochemical profiles, and gas-liquid chromatography (Jousimies-Somer and Finegold, 1991; Holdeman et al., 1977; Summanen et al., 1993). The sources of these isolates included abscesses, tissue, blood, body fluids, wounds, gastrointestinal and respiratory specimens, and bone. Because of changes in the antimicrobial composition in the test panels during the 5 years, not all strains were tested against each antimicrobial agent.

\section{Antimicrobial Agents}

Laboratory standard powders of each of the following agents were provided by the manufacturer: cefoperazone, ampicillin, and sulbactam (Roerig Pharmaceuticals, New York City, NY, USA); ceftizoxime (Fujisawa Pharmaceuticals, Deerfield, IL, USA); amoxicillin and clavulanate (SmithKline Beecham
Pharmaceuticals, Philadelphia, PA, USA); cefoxitin and imipenem (Merck Sharp and Dohme, West Point, PA, USA); cefotetan (Stuart Pharmaceuticals, Wilmington, DE, USA); piperacillin and tazobactam (Lederle Laboratories, Wayne, NJ, USA); cefotaxime (Hoechst-Roussel Pharmaceuticals, Somerville, NJ, USA); mezlocillin (Miles Pharmaceuticals, West Haven, CT, USA); ceftriaxone (Roche Laboratories, Nutley, NJ, USA); clindamycin (Upjohn, Kalamazoo, MI, USA); and metronidazole (G.D. Searle, Chicago, IL, USA). All standard powders were stored desiccated at $-20^{\circ} \mathrm{C}$ until use.

\section{Antimicrobial Susceptibility Testing}

Each strain was tested by a broth microdilution method as recommended by the National Committee for Clinical Laboratory Standards (NCCLS, 1988). Serial twofold dilutions of each antimicrobial agent (or combination) were prepared using anaerobe broth MIC (Difco) within a dilution scheme of 0.01 to $256 \mu \mathrm{g} / \mathrm{ml}$. When combining ampicillin or cefoperazone with sulbactam, or amoxicillin with clavulanate, a 2:1 ratio was used. Piperacillin was combined with tazobactam in an 8:1 ratio or a constant tazobactam concentration of $4 \mu \mathrm{g} / \mathrm{ml}$. The inoculum of each strain was prepared by inoculating 3-5 colonies into $5 \mathrm{ml}$ of pre-reduced anaerobe broth MIC and incubating for $3-6 \mathrm{~h}$ anaerobically at $35^{\circ} \mathrm{C}$. The broth culture was then adjusted to a density equal to a no. 1 McFarland nephelometer standard and further diluted to give a final inoculum size of 1 $\times 10^{5}$ colony forming units per well $\left(1 \times 10^{6} \mathrm{CFU} /\right.$ $\mathrm{ml})$. All plates were incubated for $48 \mathrm{~h}$ at $35^{\circ} \mathrm{C}$ anaerobically and then read. The MIC (minimum inhibitory concentration) was defined as the lowest concentration of each antimicrobial agent (or combination) that inhibited the visible growth of the test isolate. If trailing end points were observed, the antimicrobial concentration where the most significant reduction of growth was observed was chosen as the MIC. With each susceptibility run, quality assurance was performed with B. fragilis American Type Culture Collection (ATCC) 25285, B. thetaiotaomicron ATCC 29741, and Eubacterium lentum ATCC 43055.

\section{$\beta$-Lactamase Assay}

Production of $\beta$-lactamase was detected by using a nitrocephin test (Cefinase; BBL, Cockeysville, MD, USA).

\section{RESULTS}

Table 1 compares the in vitro activity of the various antimicrobial agents against the $B$. fragilis group. Ceftizoxime was the most active cephalosporin with 
TABLE 1 Comparison of in vitro Activity of Various Antimicrobials Against the Bacteroides fragilis Group

\begin{tabular}{|c|c|c|c|c|c|c|}
\hline Antimicrobial & $\begin{array}{l}\text { No. of } \\
\text { Strains } \\
\text { Tested } \\
\end{array}$ & Range $^{a}$ & $\begin{array}{c}\text { Mode } \\
\text { MIC }\end{array}$ & $\mathrm{MIC}_{50}$ & $\mathrm{MIC}_{90}$ & $\begin{array}{c}\% \\
\text { Resistant } \\
\end{array}$ \\
\hline Ceftizoxime & 2869 & $0.03-\geqslant 256^{a}$ & 2 & 4 & 64 & 13 \\
\hline Cefotaxime & 2868 & $0.06-\geqslant 256$ & 4 & 8 & $\geqslant 256$ & 18 \\
\hline Cefoperazone & 2734 & $0.06-\geqslant 256$ & 16 & 32 & $\geqslant 256$ & 34 \\
\hline Ceftriaxone & 1085 & $0.25-\geqslant 256$ & 2 & 8 & $\geqslant 256$ & 34 \\
\hline Cefoxitin & 2868 & $0.06 \geqslant 256$ & 8 & 16 & 32 & 6 \\
\hline Cefotetan & 2869 & $0.06-\geqslant 256$ & 8 & 8 & $\geqslant 256$ & 27 \\
\hline Cefmetazole & 742 & $0.06-\geqslant 256$ & 8 & 16 & 64 & 20 \\
\hline Piperacillin & 2869 & $0.12-\geqslant 256$ & 2 & 8 & 128 & 12 \\
\hline Mezlocillin & 1743 & $0.5-\geqslant 256$ & 8 & 8 & 128 & 12 \\
\hline Imipenem & 2371 & $0.01-32$ & 0.03 & 0.12 & 0.25 & 0.1 \\
\hline \multirow{2}{*}{$\begin{array}{l}\text { Ampicillin-sulbactam } \\
\text { Amoxicillin- } \\
\text { clavulanate }\end{array}$} & 2391 & $0.03-\geqslant 256$ & 1 & 1 & 4 & 1 \\
\hline & 1649 & $0.06-64$ & 0.5 & 0.5 & 2 & 1.4 \\
\hline \multirow{2}{*}{$\begin{array}{l}\text { Cefoperazone- } \\
\text { sulbactam }\end{array}$} & & & & & & \\
\hline & 2390 & $0.01-\geqslant 256$ & 2 & 4 & 16 & 0.7 \\
\hline $\begin{array}{l}\text { Piperacillin- } \\
\text { tazobactam }\end{array}$ & 1649 & $0.06-256$ & 1 & 2 & 16 & 02 \\
\hline Clinda & 2869 & $0.01-\geq 256$ & 0.5 & 0.5 & 8 & 14 \\
\hline Metronidazole & 2869 & $0.01-16$ & 1 & 1 & 2 & 0 \\
\hline
\end{tabular}

${ }^{a}$ Results in $\mu \mathrm{g} / \mathrm{ml}$.

${ }^{b}$ Based on NCCLS (1992) or manufacturer recommendations, the following MICs $(\mu \mathrm{g} / \mathrm{ml})$ were used as the resistant cutoff values: $\geqslant 8$, clindamycin and amoxicillin-clavulanate; $\geqslant 16$, imipenem; $\geqslant 32$, metronidazole and ampicillin-sulbactam; $\geqslant 64$, ceftizoxime, cefotaxime, cefoperazone, ceftriaxone, cefoxitin, cefotetan, cefmetazole, and cefoperazone-sulbactam; and $\geqslant 128$, mezlocillin, piperacillin, and piperacillin-tazobactam.

only $13 \%$ of the isolates being resistant and was followed by cefotaxime, cefoperazone, and ceftriaxone with resistance rates of $18 \%, 34 \%$, and $34 \%$, respectively. Among the cephamycins, resistance to cefoxitin was $6 \%$ compared with $27 \%$ and $20 \%$ to cefotetan and cefmetazole, respectively. Imipenem was the most active $\beta$-lactam agent tested, with an $\mathrm{MIC}_{90}$ of $0.25 \mu \mathrm{g} / \mathrm{ml}$ and a resistance rate of $0.1 \%$. Both piperacillin and mezlocillin showed comparable activity, with a $12 \%$ resistance rate for each. The addition of a $\beta$-lactamase inhibitor to selected $\beta$-lactams appreciably enhanced the activity of the latter compounds. A comparison of $\mathrm{MIC}_{90}$ of the $\beta$-lactam- $\beta$-lactamase inhibitor combinations indicated that amoxicillin-clavulanate was only slightly more active than ampicillin-sulbactam but eightfold more active than cefoperazone-sulbactam and piperacillin-tazobactam. Resistance rates to the combinations were low, with piperacillintazobactam having the lowest resistant rate $(0.2 \%)$. Resistance to clindamycin among the $B$. fragilis group was $14 \%$, whereas no metronidazole resistance was detected.

Table 2 compares the resistance rates of the $B$. fragilis group by test year. In general, increases in resistance over the 5 years were noted for the cephalosporins and cephamycins. Among the cephalosporins, cefoperazone resistance increased the most from $28 \%$ in 1987 to $41 \%$ in 1991 . Both ceftizoxime and cefotaxime had a $5 \%$ variation in resistance rates during the testing years while ceftriaxone resistance remained in the low to middle 30 percentages during the same period. Among cephamycins, cefotetan showed a variation in resistance rates from $22 \%$ to $31 \%$. Cefmetazole was tested only during 1989 and the resistance rate was $20 \%$ among those isolates. Cefoxitin resistance remained $<10 \%$ for each test year. Resistance rates to piperacillin and mezlocillin were similar for all years tested, but overall piperacillin resistance increased slightly more among the isolates than did resistance to mezlocillin. For imipenem and the $\beta$-lactam- $\beta$ lactamase inhibitor combinations, no consistent increase in resistance rates were observed. However, the resistance rates to clindamycin increased almost fourfold (5\%-18\%) during the 5-year period.

Table 3 compares the resistance rates of the various species of the $B$. fragilis group to the test antimicrobials. Among the cephalosporins, ceftizoxime was the most active against the various species. In 
TABLE 2 Comparison of Resistance Rates (\%) of the Bacteroides fragilis Group by Test Years

\begin{tabular}{|c|c|c|c|c|c|}
\hline \multirow[b]{2}{*}{ Antimicrobial } & \multicolumn{5}{|c|}{ Test Year } \\
\hline & 1987 & 1988 & 1989 & 1990 & 1991 \\
\hline Ceftizoxime & 11 & 10 & 12 & 15 & 15 \\
\hline Cefotaxime & 15 & 16 & 18 & 20 & 19 \\
\hline Cefoperazone & 28 & 35 & 27 & 38 & 41 \\
\hline Ceftriaxone & 32 & 35 & $\mathrm{ND}^{a}$ & 36 & ND \\
\hline \multirow{3}{*}{$\begin{array}{l}\text { Cefoxitin } \\
\text { Cefotetan } \\
\text { Cefmetazole }\end{array}$} & 8 & 5 & 5 & 6 & 8 \\
\hline & 22 & 27 & 23 & 28 & 31 \\
\hline & $\mathrm{ND}$ & ND & 20 & $\mathrm{ND}$ & ND \\
\hline \multirow{3}{*}{$\begin{array}{l}\text { Piperacillin } \\
\text { Mezlocillin } \\
\text { Imipenem }\end{array}$} & 7 & 11 & 10 & 16 & 13 \\
\hline & 11 & 10 & ND & 16 & 11 \\
\hline & 0.1 & 0.2 & 0.2 & ND & 0 \\
\hline \multirow{6}{*}{$\begin{array}{l}\text { Ampicillin- } \\
\text { sulbactam } \\
\text { Amoxicillin- } \\
\text { clavulanate } \\
\text { Cefoperazone- } \\
\text { sulbactam } \\
\text { Piperacillin- } \\
\text { tazobactam }\end{array}$} & ND & 0.6 & 1.1 & 1.4 & 0.8 \\
\hline & & & & & \\
\hline & ND & 1.8 & ND & 0.8 & 1.5 \\
\hline & D & 1 & 2.7 & .8 & 1.2 \\
\hline & & & & & \\
\hline & $\mathrm{ND}$ & 0 & $\mathrm{ND}$ & 0.4 & 0.2 \\
\hline Clind & 5 & 11 & 13 & 19 & 18 \\
\hline Metronidazole & 0 & 0 & 0 & 0 & 0 \\
\hline
\end{tabular}

${ }^{a}$ Not done.

contrast, resistance rates to cefoperazone and ceftriaxone were very high among the non- $B$. fragilis species. Among the cephamycins, resistance rates to cefotetan and cefmetazole were high among $B$. thetaiotaomicron, B. ovatus, and B. distasonis. Cefoxitin was the most active cephamycin, but increased resistance was noted among the non- $B$. fragilis species compared with the $B$. fragilis species. Resistance rates to piperacillin and mezlocillin were similar among the various species; however, resistance rates were higher among non- $B$. fragilis species. Only a few strains of $B$. fragilis exhibited resistance to imipenem. Resistance to all $\beta$-lactam $/ \beta$-lactamase inhibitor combinations was noted, but the highest rates were noted among $B$. distasonis and $B$. ovatus. Strains of non- $B$. fragilis species were appreciably more resistant to clindamycin than were $B$. fragilis strains.

\section{DISCUSSION}

The resistance rates of the $B$. fragilis group to various antimicrobial agents have been reported to be both species and geographically dependent (Aldridge et al., 1984; Aldridge et al., 1988; Tally et al., 1985). The predominant mechanism of resistance to $\beta$-lactams among the $B$. fragilis group is $\beta$-lactamase production (Nord et al., 1985). Although the most common $\beta$-lactamases from these isolates are characterized as cephalosporinases, some $B$. fragilis group strains elaborate $\beta$-lactamases capable of destroying antimicrobials considered $\beta$-lactamase stable such as cefoxitin, imipenem, and piperacillin (Cuchural et al., 1983; Sato et al., 1982). Moreover, $\beta$-lactamasemediated cefoxitin resistance among strains of the $B$. fragilis group has been shown to be transferable (Cuchural et al., 1986a).

Results of the present study confirm that there are significant differences in the activity of certain antimicrobial agents against $B$. fragilis group isolates. Among the single agents tested, metronidazole and imipenem were the most active. Among the cephalosporin compounds, ceftizoxime was more active than cefotaxime, cefoperazone, and ceftriaxone, while among cephamycins, cefoxitin was more active than cefotetan and cefmetazole. Piperacillin, mezlocillin, and clindamycin had comparable resistance rates. With the exception of imipenem, the non- $B$. fragilis species were significantly more resistant to the $\beta$-lactam antimicrobials alone (no $\beta$-lactamase inhibitor) than were strains of the $B$. fragilis species; a similar pattern was seen with clindamycin.

Prevention of $\beta$-lactam degradation by addition of a $\beta$-lactamase inhibitor has proven to be very effective. The addition of sulbactam, clavulanate, or tazobactam significantly reduced the resistance rates to the accompanying $\beta$-lactams and potentiated the activity of the antimicrobials by reducing the mode MICs and MIC $_{90}$ up to 32-fold and 64-fold, respectively. One strain of $B$. fragilis resistant to all of the $\beta$-lactam- $\beta$-lactamase inhibitor combinations except piperacillin-tazobactam was also resistant to all other $\beta$-lactams tested. This strain probably produces the metallo-containing $\beta$-lactamase enzyme that has been shown to destroy all penicillins and cephalosporins (Cuchural et al., 1986b).

A comparison of our data with the recent US reports by Cuchural et al. (1988 and 1990) shows similarities and differences. Overall, the two reports correlated well with regard to resistance rates to imipenem, cefoxitin, piperacillin, cefoperazone, and clindamycin. However, reported resistance rates of $22 \%, 23 \%$, and $14 \%$ to ceftizoxime, cefotaxime, and cefotetan, respectively, differed from our results showing resistance rates of $13 \%, 18 \%$, and $27 \%$ to the same antimicrobials. Furthermore, the ceftizoxime $\mathrm{MIC}_{90}$ in our study was $64 \mu \mathrm{g} / \mathrm{ml}$ compared with $\geqslant 128 \mu \mathrm{g} / \mathrm{ml}$ in their study. Our ceftizoxime data are in contrast to theirs and, from a comparison of our in vitro data, we can conclude that ceftizoxime has good coverage against $B$. fragilis group isolates with 
TABLE 3 Comparison of Resistance Rates (\%) of the Various Species of the Bacteroides fragilis Group to the Antimicrobials

\begin{tabular}{|c|c|c|c|c|c|c|}
\hline \multirow[b]{2}{*}{ Antimicrobial } & \multicolumn{6}{|c|}{ Bacteroides } \\
\hline & fragilis & $\begin{array}{l}\text { thetalotao- } \\
\text { micron }\end{array}$ & ovatus & distasonis & vulgatus & Other ${ }^{a}$ \\
\hline Ceftizoxime & 11 & 16 & 15 & 17 & 8 & 11 \\
\hline Cefotaxime & 16 & 23 & 23 & 20 & 11 & 21 \\
\hline Cefoperazone & 25 & 51 & 57 & 31 & 25 & 12 \\
\hline Ceftriaxone & 19 & 72 & 58 & 46 & 31 & 31 \\
\hline Cefoxitin & 4 & 9 & 12 & 12 & 9 & 15 \\
\hline Cefotetan & 8 & 51 & 67 & 53 & 20 & 29 \\
\hline Cefmetazole & 0 & 0 & 0 & 0 & 0 & 33 \\
\hline Piperacillin & 9 & 13 & 16 & 17 & 18 & 9 \\
\hline Mezlocillin & 11 & 11 & 14 & 19 & 16 & 8 \\
\hline Imipenem & 0.2 & 0 & 0 & 0 & 0 & 0 \\
\hline $\begin{array}{l}\text { Ampicillin- } \\
\text { sulbactam }\end{array}$ & 0.7 & 0.5 & 1.4 & 5 & 0 & 0 \\
\hline $\begin{array}{l}\text { Amoxicillin- } \\
\text { clavulanate }\end{array}$ & 1.0 & 1.6 & 2.5 & 4.3 & 0 & 0 \\
\hline $\begin{array}{l}\text { Cefoperazone- } \\
\text { sulbactam }\end{array}$ & 1.8 & 2.7 & 3.1 & 0.7 & 1.4 & 0 \\
\hline $\begin{array}{l}\text { Piperacillin- } \\
\text { tazobactam }\end{array}$ & 0.1 & 0.4 & 0.4 & 0 & 0 & 0 \\
\hline Clindamycin & 8 & 20 & 26 & 22 & 18 & 13 \\
\hline Metronidazole & 0 & 0 & 0 & 0 & 0 & 0 \\
\hline
\end{tabular}

${ }^{a}$ Contains 25 B. uniformis, 10 B. caccae, and 1 B. eggerthii.

activity comparable to that of clindamycin. A clinical study by Bennion et al. (1992) in patients with perforated or gangrenous appendicitis with peritonitis reported that ceftizoxime exhibited good antianaerobic coverage. These differences in in vitro results are probably related to differences in susceptibility testing methodologies (Aldridge and Sanders, 1987; Aldridge et al., 1990).

Other US investigators have reported the high level of activity with $\beta$-lactam- $\beta$-lactamase inhibitor combinations with results similar to ours. Barry et al. (1986) reported that sulbactam reduced the $\mathrm{MIC}_{90}$ of ampicillin and cefoperazone from $\geqslant 16 \mu \mathrm{g} / \mathrm{ml}$ to 2 $\mu \mathrm{g} / \mathrm{ml}$ and from $128 \mu \mathrm{g} / \mathrm{ml}$ to $16 \mu \mathrm{g} / \mathrm{ml}$, respectively. Wexler et al. (1985) showed an $\mathrm{MIC}_{90}$ reduction from $\geqslant 256 \mu \mathrm{g} / \mathrm{ml}$ to $8 \mu \mathrm{g} / \mathrm{ml}$ when sulbactam was added to ampicillin. Clavulanate has been reported to increase the activity of amoxicillin 16-fold (Barry et al., 1986). Appelbaum et al. (1986) have also shown a significant increase in the activity of piperacillin in the presence of tazobactam (YTR 830). In our study, ampicillin-sulbactam and amoxicillinclavulanate appeared to be slightly more active (MICs) than the other $\beta$-lactam- $\beta$-lactamase inhibitor combinations; however, no appreciable differences in resistance rates were noted. Currently the approach of protecting $\beta$-lactams with $\beta$-lactamase inhibitors appears to remain highly effective.

Phillips et al. (1992) reported on an in vitro survey of the susceptibility of $B$. fragilis group by using broth microdilution testing of isolates from 15 European and Scandinavian countries. Their results were similar to ours with regard to amoxicillinclavulanate, cefoxitin, cefotetan, imipenem, and metronidazole. Similarly we found imipenem resistance among $B$. fragilis strains. Notable differences for overall results were that mezlocillin resistance was $12 \%$ in our study versus $6 \%$ in theirs, and clindamycin resistance was higher in our study (14\% versus $9 \%$ ). Our higher rates of clindamycin resistance more closely agree with reports from Spain and France (Dubreuil et al., 1992; Reig et al., 1984; Garcia-Rodriquez and Garcia-Sanchez, 1985). In Japan, a report by Watanabe et al. (1992) described susceptibility patterns of $B$. fragilis and $B$. thetaiotaomicron strains. Resistance to imipenem was found among both groups of isolates, with resistance rates of $1.6 \%$ and $3.4 \%$, respectively. They also reported good activity for ceftizoxime and cefoperazonesulbactam similar to ours. For the two test groups, they reported clindamycin resistances of $24 \%$ and $27.5 \%$, respectively. Moreover, their piperacillin re- 
sistance rate among $B$. thetaiotaomicron was $26.8 \%$ compared with our $13 \%$. Fortunately no metrondazole resistance was noted.

This study has shown that a variety of susceptibility patterns can be observed among strains of the $B$. fragilis group. Currently metronidazole, imipenem, and the $\beta$-lactam- $\beta$-lactamase inhibitor combinations are the most active. Good activity was also seen for mezlocillin, piperacillin, ceftizoxime, cefoxitin, and clindamycin. Because of reports of resistance to metronidazole, imipenem, and other antimicrobials among anaerobes (Breuil et al., 1989;

\section{REFERENCES}

Aldridge KE, Sanders CV (1987) Antibiotic- and methoddependent variation in susceptibility testing results of Bacteroides fragilis group isolates. I Clin Microbiol 25: 2317-2321.

Aldridge KE, Sanders CV, Janney A, Faro S, Marier RL (1984) Comparison of the activities of penicillin $G$ and new $\beta$-lactam antibiotics against clinical isolates of $\mathrm{Bac}$ teroides species. Antimicrob Agents Chemother 26:11811188.

Aldridge KE, Henderberg A, Schiro DD, Sanders CV (1988) Susceptibility of Bacteroides fragilis group isolates to broad-spectrum $\beta$-lactams, clindamycin, and metronidazole: rates of resistance, cross-resistance, and importance of $\beta$-lactamase production. Adv Ther 5:273 282.

Aldridge KE, Wexler HM, Sanders CV, Finegold SM (1990) Comparison of in vitro antibiograms of Bacteroides fragilis group isolates: differences in resistance rates in two institutions because of differences in susceptibility testing methodology. Antimicrob Agents Chemother 34:179-181.

Appelbaum PC, Jacobs MR, Spangler JK, Yamabe S (1986) Comparative activity of $\beta$-lactamase inhibitors YTR 830 , clavulanate, and sulbactam combined with $\beta$-lactams against $\beta$-lactamase producing anaerobes. Antimicrob Agents Chemother 30:789-791.

Barry AL, Jones RN, Packer RR (1986) In vitro susceptibility of the Bacteroides fragilis group to cefoperazone, ampicillin, ticarcillin, and amoxycillin combined with $\beta$-lactamase inhibitors. I Antimicrob Chemother 17:125127.

Bennion RS, Thompson JE Jr, Baron EJ, Schmit RJ, Fine gold SM (1992) The use of single agent antibiotic regimens in the treatment of advanced appendicitis with peritonitis. Drug Invest 4(Suppl 1):7-12.

Breuil J, Burnat C, Patey O, Dublanchet A (1989) Survey of Bacteroides fragilis susceptibility patterns in France. I Antimicrob Chemother 24:69-75.

Brogan O, Garnett PA, Brown R (1989) Bacteroides fragilis resistant to metronidazole, clindamycin, and cefoxitin. J Antimicrob Chemother 23:660-662.

Brook I (1988) Recovery of anaerobic bacteria from clinical specimens in 12 years at two military hospitals. J Clin Microbiol 26:1181-1188.

Cuchural GJ Jr, Tally FP, Jacobus NV, Marsh PK, Mayhew
Brogan et al., 1989; LaMothe et al., 1986), additional in vitro studies to monitor changes in susceptibility patterns are warranted not only in the United States but elsewhere.

The authors thank the following individuals for excellent technical assistance: C.J. Robichaux, J. Grogan, S. Dembeck, F. Kohan, R. Paxon, J. Barnishan, M. Katz, D. Moss, L. Johnson, I. Kowalski, and R. Ressler. This study was supported by grants from Roerig Pharmaceuticals, Fujisawa Pharmaceuticals, and Smith Kline Beecham Laboratories.

JW (1983) Cefoxitin inactivation by Bacteroides fragilis. Antimicrob Agents Chemother 24:936-940.

Cuchural GJ Jr, Tally FP, Storey JR, Malamy MH (1986a) Transfer of $\beta$-lactamase-associated cefoxitin resistance in Bacteroides fragilis. Antimicrob Agents Chemother 29: 918-920.

Cuchural GJ Jr, Malamy MH, Tally FP (1986b) $\beta$-Lactamase-mediated imipenem resistance in Bacteroides fragilis. Antimicrob Agents Chemother 30:645-648.

Cuchural GJ Jr, Tally FP, Jacobus NV, Aldridge K, Cleary T, Finegold SM, Hill G, Iannini P, O'Keefe P, Pierson C, Crook D, Russo T, Hecht D (1988) Susceptibility of the Bacteroides fragilis group in the United States: analysis by site of isolation. Antimicrob Agents Chemother 32:717-722.

Cuchural GJ Jr, Tally FP, Jacobus NV, Cleary T, Finegold SM, Hill G, Iannini P, O'Keefe JP, Pierson C (1990) Comparative activities of newer $\beta$-lactam agents against members of the Bacteroides fragilis group. Antimicrob Agents Chemother 34:479-480.

Dubreuil L, Breuil J, Dublanchet A, Sedallian A (1992) Survey of the susceptibility patterns of Bacteroides fragilis group strains in France from 1977 to 1992. Eur J Clin Microbiol Infect Dis 11:1094-1099.

Finegold SM, George WL (eds) (1989) Anaerobic Infections in Humans. San Diego: Academic.

Garcia-Rodriquez JA, Garcia-Sanchez JE (1985) Evolution of the Bacteroides fragilis group antimicrobial susceptibility in Spain. Chemotherapia 4(Suppl 2):806-808.

Goldstein EJC, Citron DM (1988) Annual incidence, epidemiology, and comparative in vitro susceptibilities to cefoxitin, cefotetan, cefmetazole and ceftizoxime to recent community-acquired isolates of the Bacteroides fragilis group. J Clin Microbiol 26:2361-2366.

Holdeman LV, Cato EP, Moore WEC (1977) Anaerobe Laboratory Manual, 4th ed. Blackburg, VI: Virginia Polytechnic Institute and State University.

Jousimies-Somer HR, Finegold SM (1991) Anaerobic Gram-negative bacilli and cocci. In Manual of Clinical Microbiology, 5th ed. Eds, A Balows, WJ Hausler Jr, KL Herrmann, HD Isenberg, and $\mathrm{H}$ Shadomy. Washington, DC: American Society for Microbiology, pp 538 552.

LaMothe F, Fijalkowski C, Malouin F, Bourgault AM, Delorme L (1986) Bacteroides fragilis resistant to both met- 
ronidazole and imipenem. I Antimicrob Chemother 18: 642-643.

National Committee for Clinical Laboratory Standards (NCCLS) (1988) Tentative standard M11-T2: methods for antimicrobial susceptibility testing of anaerobic bacteria. Villanova, PA: NCCLS.

National Committee for Clinical Laboratory Standards (NCCLS) (1990) Approved standard M11-A2: methods for antimicrobial susceptibility testing of anaerobic bacteria. Villanova, PA: NCCLS.

National Committee for Clinical Laboratory Standards (NCCLS) (1992) Informational supplement M100-S4: performance standards for antimicrobial susceptibility testing. Villanova, PA: NCCLS.

Nord CE, Lindquist L, Olsson-Liljequist B, Tuner K (1985) Beta-lactamases in anaerobic bacteria. Scand J Infect Dis 46(Suppl):57-63.

Phillips I, King A, Nord CE, Hoffstedt B (1992) Antibiotic sensitivity of the Bacteroides fragilis group in Europe. Eur I Clin Microbiol Infect Dis 11:292-304.

Reig M, Campello MG, Baquero F (1984) Epidemiology of clindamycin resistance in the Bacteroides fragilis group. I Antimicrob Chemother 14:595-603.

Sato K, Matsura Y, Inowe M, Mitsuhashi S (1982) Properties of a new pencillinase type produced by Bacteroides fragilis. Antimicrob Agents Chemother 22:579-584.

Summanen P, Baron EJ, Citron DM, Strong CA, Wexler HM, Finegold SM (1993) Wadsworth Anaerobic Bacteriology Manual, 5th ed. Belmont, CA: Star.

Tally FP, Cuchural GJ Jr, Jacobus NV, Gorbach SL, Aldridge $K$, Cleary $T$, Finegold $S M$, Hill $G$, Iannini $P$, $\mathrm{O}^{\prime}$ Keefe JP, Pierson C (1985) Nationwide study of susceptibility of the Bacteroides fragilis group in the United States. Antimicrob Agents Chemother 28:675-677.

Watanabe K, Ueno K, Kato N, Muto $Y$, Bandoh K, Tanaka Y, Jotwani R, Goto M, Shimada K, Shimizu K, Goto S, Hara K (1992) In vitro susceptibility of clinical isolates of Bacteroides fragilis and Bacteroides thetaiotaomicron in Japan. Eur J Clin Microbiol Infect Dis 11:1069-1073.

Wexler HM, Harris B, Carter WJ, Finegold SM (1985) In vitro efficacy of sulbactam combined with ampicillin against anaerobic bacteria. Antimicrob Agents Chemother $27: 876-878$ 